Belfast

chrisbaraniuk@gmail.com

Cite this as: BMJ2022;376:0158

http://dx.doi.org/10.1136/bmj.0158

Published: 20 January 2022

\section{Covid-19: How Europe is approaching long covid}

\section{Chris Baraniuk looks at the range of responses to long covid around the continent}

\section{Chris Baraniuk freelance journalist}

Maarte Preller leads a Facebook group for patients with long covid in Austria. It has nearly 1500 members so far. In September, Preller, and others like her across Europe, established a new network of patient associations, formed partly through social media websites, called Long Covid Europe. The group is demanding better research and treatment for the tangle of ongoing symptoms that afflict many people who have had covid-19.

A patchwork of small studies has given some indication of what long covid on the continent is like. In a study of 130 cases, $40 \%$ of patients reported "persistent fatigue" 60 days after their first symptoms, while 30\% reported breathlessness. Another, of 143 patients in Italy, revealed $55 \%$ had three or more symptoms 60 days after they were discharged from hospital. 1

A preprint posted in January 2022 of an ongoing study of 70 ooo Norwegian patients listed altered smell or taste, poor memory, fatigue, and shortness of breath as common symptoms in the country's first wave (in early 2021), while those infected from autumn 2021 onwards tended to mention muscle and joint pain more. The data suggest that symptoms were experienced for 11-12 months after infection in the first wave and for one to two months in the second. ${ }^{2}$

A World Health Organization policy brief published earlier this year found that surveillance of long covid was not happening routinely in European countries. ${ }^{1}$ There are few specialist clinics for the condition-access to such a service largely depends on where you live-and in many countries action seems to be limited to guidance and monitoring.

\section{The many faces of action}

In the UK, there are more than 80 NHS run long covid clinics. Long covid services were highlighted as part of $€ 6.6 \mathrm{bn}$ in new funding announced in March 2021 for the ongoing NHS response to the pandemic. ${ }^{3}$ Separately, the Scottish government has announced €1om in funding for local health boards to help patients who have long term symptoms.

In the European Union, specialist long covid clinics are reported to be operating in Belgium, France, Germany, and Spain, among others, but these rarely cater for more than a small part of the population.

In Italy, no government funded clinics for long covid have yet been established, according to Danilo Buonsenso at Gemelli University Hospital in Rome, although some hospitals have day clinics for following up patients who had been admitted to hospital during the acute stage of covid-19. A few of the day clinics include patients who have no history of hospital admission for covid-19, however, "the waiting list is incredibly high,” Buonsenso adds.

In May 2021, the Italian government allocated around $€ 28 \mathrm{~m}$ for 2021 and $€ 24 \mathrm{~m}$ for 2022 , to the "respiratory care" of covid-19 patients who had been admitted to hospital. ${ }^{4}$ In July, Italy's National Institute of Health (ISS) published a report on interim indications on long covid management, ${ }^{5}$ which refers to the need for specialist "post-covid clinics" as well as facilities linked to general practice and hospitals.

The French National Authority for Health (HAS) published official guidelines for the follow-up of long covid patients in February 2021, stating that most can be followed up through primary care.

This echoes an initiative in Belgium. Ann Li, Long Covid Europe's representative for Belgium, told The $B M J$ in late 2021 that there was a primary care initiative from Belgium's National Institute for Health and Disability Insurance, ordered by the minister of health. "Some specialists, assurance companies, and professional associations from [the primary healthcare sector]are part of the initiative. The tool should be ready by the end of this year and should make it easier for our primary care workers to plan rehabilitation for long haulers. It will include a financial compensation plan for patients who visit psychologists, dieticians, or physiotherapists." The tool is now expected to launch in the spring of 2022, $\mathrm{Li}$ added later.

In Spain, two doctors recently received a grant of $€ 1.8 \mathrm{~m}$ from the Spanish government to open a clinic for long covid patients. One of the pair, César Fernández-de-las-Peñas, a physical therapist at Rey Juan Carlos University, told The BMJ that the clinic would be "the first post-covid healthcare unit in Spain” when it opens, possibly as soon as March 2022. They also received $€ 1 \mathrm{~m}$ funding for long covid research.

In Norway last summer, the then health minister, Bent Høie, asked hospitals to establish outpatient clinics for people with long covid. There are now four in total, one for each health region in the country. A spokesman for Norway's health directorate told The $B M J$ that there is a "national action plan" focusing on providing information about the condition for patients. "We have also developed guidance for healthcare workers on how to detect and treat people having post-covid symptoms," the spokesman says. They added, however, that the actual treatment delivered will depend on the clinic in question and that it is down to individual doctors to recommend a plan for each patient.

In neighbouring Sweden, Judith Bruchfeld, physician at Karolinska University Hospital, who leads a 
research project on long covid, helped the National Board of Health and Welfare to implement guidelines for follow-up. But support for care or further research has been unforthcoming. "Long covid is new and complex, and resources are needed,” says Bruchfeld, adding that only seven out of 21 regions were able to run a long covid clinic.

Estonia is also providing guidance to healthcare workers. Heidi Alasepp, deputy secretary general on health at Estonia's ministry of social affairs, says, "Guidance and training has been given to GPs and specialists to raise awareness and provide advice on how to deal with long covid.” There's no plan for specialist clinics, but the ministry has launched a covid-19 patient follow-up study that will cover a 12 month period.

WHO definition
WHO set a clinical case definition in October $2020^{6}$ and added "post
covid-19 condition" to the International Classification of Diseases codes
used to "document or flag conditions that occur in the context of covid-19.
In particular, the need for disambiguation between acute disease, late
effects, or lengthy course led to the neutral formulation 'post-covid."”7
The WHO Regional Office for Europe did not respond to a BMJ request for
comment.
Post covid-19 condition occurs in people with a history of probable or
confirmed SARS-CoV-2 infection, usually three months from the onset of
covid-19 with symptoms that last for at least two months that cannot be
explained by an alternative diagnosis. Common symptoms include fatigue,
shortness of breath, and cognitive dysfunction, but also others, and
generally have an impact on everyday functioning. Symptoms may be
new onset following initial recovery from an acute covid-19 episode or
persist from the initial illness. Symptoms may also fluctuate or relapse
over time.

\section{Research gap}

Carmen Scheibenbogen, professor of immunology at Charité University in Berlin, says she currently has two or three patient enquiries for every appointment available at her clinic.

"We need to put more effort into research," she says. "In Germany, at least, we don't have much funding at the moment for these post-covid syndromes.” The German Ministry of Education and Research has allocated $€ 6.5 \mathrm{~m}$ to 10 projects investigating the condition. The French government's budget for long covid research is $€ 2.2 \mathrm{~m}$, according to France $24 .{ }^{8}$ In contrast, the UK has allocated nearly £2om in funding to research the condition.

Dominique Salmon-Ceron, an infectious disease researcher at the Hôtel-Dieu Hospital in Paris, told France24 in June that she had applied for funding four times in the past year, only to be declined by the health ministry.

In May, the European Commission said it would accelerate research into long covid and seek to develop treatments as part of its covid-19 therapeutics plan. ${ }^{9}$ But no further details or specific funding has been revealed. A spokeswoman for the European Medicines Agency told The BMJ that "none of the treatments that are currently under the EMA's evaluation are intended for long covid."

Long Covid Europe's representatives say they want to see more patient focused research, and longer term follow-up to ensure that clinics have had a positive impact on patients, among other things. There is also a need for improved services for children with long covid, they say.

Bigger and more coordinated treatment trials could, in theory, help to enable that. Mark Toshner, lecturer in translational respiratory research at the University of Cambridge, who is involved in a UK trial of long covid treatments, ${ }^{10}$ says Europe-and the rest of the world-will be missing a trick if experiments with existing drugs or therapies as treatments for long covid aren't wrapped into formalised, international trials. He points out that thousands of patients need to be enrolled in studies like this to achieve useful results.

As Nina Langeland, professor of infectious diseases at the University of Bergen in Norway, put it, when it comes to long covid, "we're all lagging behind, that's my worry."

I have read and understood BMJ policy on declaration of interests and have no relevant interests to declare.

Commissioned, externally peer reviewed

WHO Europe. In the wake of the pandemic: preparing for long covid (2021). www.eu-

ro.who.int/en/health-topics/health-emergencies/coronavirus-covid-19/publications-and-technicalguidance/2021/in-the-wake-of-the-pandemic-preparing-for-long-covid-2021

2 Caspersen $\mathrm{IH}$, Magnus P, Trogstad L. Excess risk and clusters of symptoms after covid-19 in a large Norwegian cohort.Medrxiv 2021:2021.10.15.21265038 [Preprint]. doi: 10.1101/2021.10.15.21265038

3 Department of Health and Social Care. $\mathrm{f} 7$ billion for NHS and social care for covid-19 response and recovery. 18 March 2021. www.gov.uk/government/news/7billion-for-nhs-and-social-carefor-covid-19-response-and-recovery

4 Urgent measures related to the covid-19 emergency, for business, work, young people, health and local services. [Italian]. Gazzetta Ufficiale. 25 May 2021. www.gazzettaufficiale.it/eli/id/2021/05/25/21G00084/sg

5 Onder G, Floridia M, Giuliano M. at al. Interim guidance on long covid management principles. ISS. 1 July 2021. www. Iss.it/documents/20126/0/Rapporto+ISS+COVID-

19+n.15_2021_EN.pdf/dd962ad9-fa53-73dd-7759-55cb5c167675?t=1627575304593

6 WHO. A clinical case definition of post covid-19 condition by a Delphi consensus. 6 October 2021 www.who.int/publications/i/item/WHO-2019-nCoV-Post_COVID-19_condition-ClinicaL_case_definition-2021.1

7 WHO. Emergency use ICD codes for covid-19 disease outbreak. www. who.int/standards/classifications/classification-of-diseases/emergency-use-icd-codes-for-covid-19-disease-outbreak

8 Paccalin C. Fighting long covid: sufferers in France search for answers. France24. 26 June 2021 www.france24.com/en/tv-shows/reporters/20210626-fighting-long-covid-sufferers-in-francesearch-for-answers

9 European Commission. EU strategy on covid-19 therapeutics. 6 May 2021. https://ec.europa.eu/info/sites/default/files/communication-strategy-covid-19-therapeutics_en.pdf

10 Heal-Covid. https://heal-covid.net

This article is made freely available for personal use in accordance with BMJ's website terms and conditions for the duration of the covid-19 pandemic or until otherwise determined by BMJ. You may download and print the article for any lawful, non-commercial purpose (including text and data mining) provided that all copyright notices and trade marks are retained. 